\title{
Assessing the Consuption of Alternative Sources of Energy: A Detailed Analysis in Low and High Areas of Kabulonga and Chawama Townships of Lusaka City
}

\author{
Catherine Kafuchi Chipoya ${ }^{1}$, Mundia Muya ${ }^{1}$, Sam Sichilalu ${ }^{2}$ \\ ${ }^{1}$ School of Engineering, University of Zambia, Lusaka, Zambia \\ ${ }^{2}$ School of Engineering Electrical and Electronic Engineering, University of Zambia, Lusaka, Zambia
}

Email address:

cathychipo@gmail.com (C. K. Chipoya), mmuya@unza.zm (M. Muya), sichgroup@yahoo.com(S. Sichilalu)

To cite this article:

Catherine Kafuchi Chipoya, Mundia Muya, Sam Sichilalu. Assessing the Consuption of Alternative Sources of Energy: A Detailed Analysis in Low and High Areas of Kabulonga and Chawama Townships of Lusaka City. Journal of Energy and Natural Resources.

Vol. 8, No. 2, 2019, pp. 66-76. doi: 10.11648/j.jenr.20190802.14

Received: March 8, 2019; Accepted: April 17, 2019; Published: May 31, 2019

\begin{abstract}
Providing sustainable energy access is one of the most critical global challenges. Both developed and developing nations depend on a variety of primary energy sources like coal, natural gas, biomass, oil and renewable energy to produce electricity. Following the power deficit that was experienced in Zambia between 2015 and 2017 the government has been doing everything possible to develop a diversified renewable energy sector that will play a pivotal role in the provision of alternative sources of energy in the country. However, the intensifying levels of load shedding forced domestic consumers to resort to alternative sources of energy such as; charcoal, generators and gas stoves. This paper assesses the consumption and sustainability of alternative energy sources in high and low density population areas in Lusaka and focusing on households. The study was done on a representative sample of Lusaka from two areas namely Kabulonga, and Chawama representing low and high density respectively. Data was obtained through administering questionnaires to household heads. Results showed that energy consumption behaviour of households varies from one region to another and not all factors are equally important in determining energy consumption in different areas and regions. It was also revealed that the energy consumption decision is affected by economic factors such as market price of fuel, household income, household expenditures and noneconomic factors which include; a set of household characteristics such as household size, gender, education, house ownership, type of dwelling, location of residence, household age, distance to fuel source, and access to electricity. The results showed that $36 \%$ respondents in Kabulonga use electricity against $31.1 \%$ in Chawama, $29 \%$ use gas in Kabulonga against 26\% in Chawama. It was noted that more respondents in Chawama use solar at $8.9 \%$ against $2 \%$ in Kabulonga and also that those that use charcoal in Chawama were $26.7 \%$ more than the Charcoal users in Kabulonga at $11 \%$. While the government of Zambia is working on resolving power challenges that the country recently faced, building more hydropower stations has remained their focus. These major hydropower developments will not likely solve the power deficit or climate change effects being experienced such as low water levels due to droughts.
\end{abstract}

Keywords: Energy, Sustainable, Renewable, Non-Renewable, Consumption, Electricity

\section{Introduction}

Energy is a key element in the development of a nation. It is needed both in residential and business corporations in running of the day to day activities. Its importance in powering the economy is something that is totally agreed upon by many scholars and proponents alike [1-2]. The residents from the two areas of interest have alternative sources of energy available as the country, Zambia is endowed with a lot of natural resources and has a mix of energy sources that include; biomass, coal, petroleum, solar and Hydro power [3]. Even with all these energy sources available, the residents in the two areas have not been spared from the challenges of energy deficit. This is mainly because Zambia as a nation has been dependent on only one source of energy, hydro power [3]. Most of the electricity is generated from Kariba Dam, a man made dam jointly owned by 
Zambia and Zimbabwe and solely constructed between 1955 and 1959 for power generation in both countries [4].

In 2015, Zambia experienced abnormal power load shedding which were as a result of energy deficit. There.

had been population increase which led to high demand of electricity. According to the census reports, there has been an increase of the Zambian population which in estimated to be growing at an average rate of $2.8 \%$ that is, from the total population of 4,056,995 in 1969 to 5,661,801 in $19807,383,097$ in 1990, 9,885,591 in 2000, 13,092,666 in 2010 and 15,023,315 in 2014 respectively [5]. According to the latest United Nations population estimates report, the population of Zambia had grown to $17,946,037$ [6] by the year 2018. This increase in population led to an increase in electricity demand and forced people to resort to other energy sources.

This paper assess the consumption and sustainability of alternative energy sources of energy in the townships of Kabulonga and Chawama, low and high density areas of Lusaka city respectively.

\section{Literature Review}

Zambia is a land locked country located in the southerncentral region of Africa with an estimated population of $17,946,037$ [6].It is made up of 10 provinces and Lusaka being the capital city is the most populated. It is surrounded by eight (8) countries namely; Malawi, Tanzania, Democratic republic of Congo, Angola, Botswana, Namibia, Mozambique and Zimbabwe [1, 2, 7, 8]. The country operates a single-buyer model where Zambia Electricity Supply Corporation limited (ZESCO) a government parasternal buys, generates, transmits and distributes electricity in the country. As earlier mentioned in the introduction, the electricity generation mix is mainly made up of hydro-power which takes up over $95 \%$ of the total generation. Some Private Power Producers (PPP) such as Lunsemfwa Hydro Power Company (LHPC), Ndola Energy Company Limited (NECL), Zengamina Power Limited (ZPL) and the Copperbelt Energy Corporation (CEC) had come on board by 2013.CEC a private owned company transmits and distributes electricity to the Zambian mines on the copperbelt while LHPC, NEC and ZPL distribute to rural areas and mining communities [9].

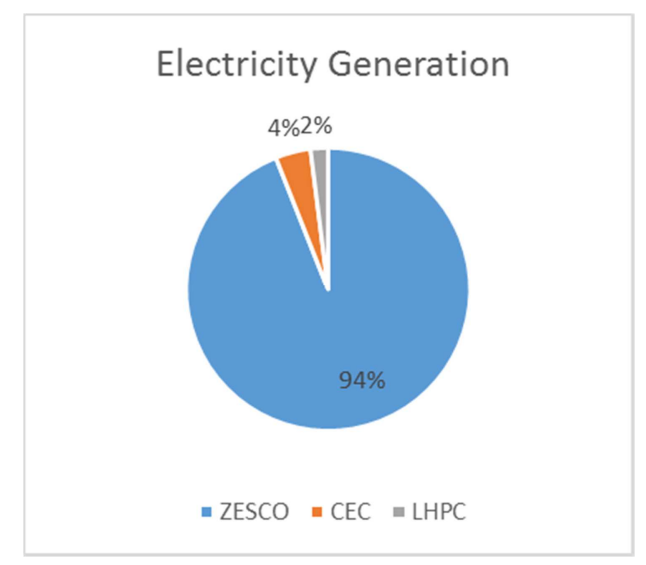

Figure 1. Electricity Generation.

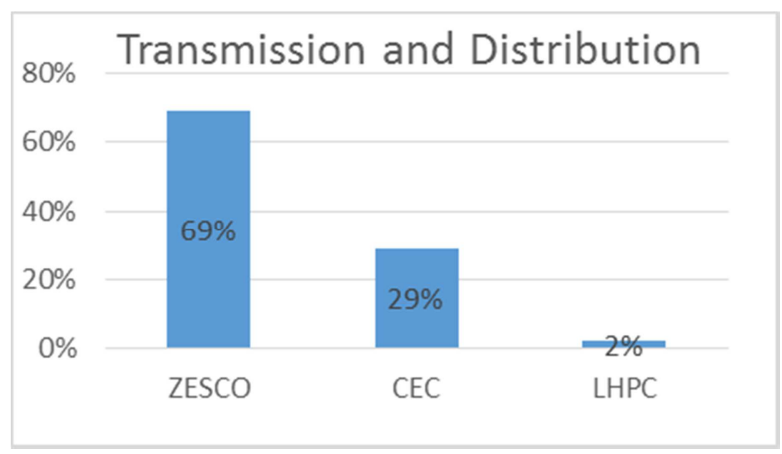

Figure 2. Electricity Generation and Distribution.

Figure 2 shows the electricity generation capabilities by company. It can be seen from the charts above that ZESCO generates more electricity at $94 \%$ followed by CEC at $4 \%$ and the least producer being LHPC at $2 \%$. The transmission and distribution follows the same order with ZESCO, CEC and LHPC at 69\%, 29\%, 2\% respectively.

\section{Energy Consumption and Sustainability}

\subsection{Energy Consumption}

Energy is needed in both residential and industries. It is used for production, cooking, heating, lighting and boiling water. The usage of energy in whatever form is what is referred to as energy consumption. Since 2015 when the country under went energy deficit, most people resorted to other sources of energy such as; Charcoal, generators, solar and gas. The decision on which energy source to use was affected by economic factors such as market price of fuel, household income, household expenditures and noneconomic factors which include a set of household characteristics such as household size, gender, education, house ownership, type of dwelling, location of residence, household age, distance to fuel source, and access to electricity. It should be noted that while $95 \%$ of electricity generated is from hydro, $69 \%$ is consumed by the mining industry. It is also important to note that $95 \%$ of the Zambian population consume woodfuel posing a threat for deforestation. Even though $66 \%$ of Zambia's total land area is covered by the forest, this is being lost as a result of population increase putting pressure on the woodlands [10].

The demand for electricity in a low density area like Kabulonga was found to be higher compared to a high density area like Chawama due to the difference in the lifestyles. Energy in households is consumed by refrigerators, washing machines, desktop computers, copiers, printers, and coolers, and stoves. Buying energy efficient appliances will help people manage the energy bills in their homes [11]. It should be noted that improving energy efficiency before increasing energy supply is generally the more economically efficient approach. The type of electrical appliances in households determine the demand for electricity. Energy inefficient appliances consume a lot of electricity [9]. It should be noted that people both in Kabulonga 
and chawama have little information on energy efficient appliances. The government of Zambia has embarked on the project to sensitise people on the benefits of using energy efficient appliances and other sources of energy. As a way of promoting the usage of energy efficient appliances and sustainable sources of energy, the government has also removed import duties on all energy appliances [11-12].

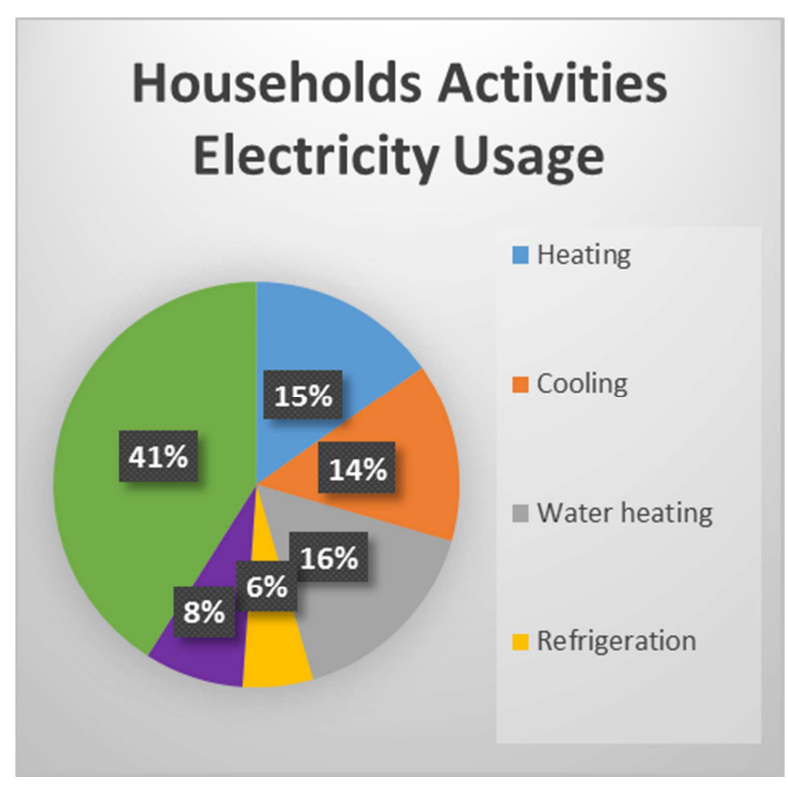

Figure 3. Households activities and electricity usage.

The figure above shows activities in house households that consume energy. It can be seen from the chart that computerslelectronics and cooking activities consume about $41 \%$ of the total energy in homes. This explains the more reason why Kabulonga a low density area has high demand for electricity. The households in Kabulonga have more electrical appliances and high life styles that demand for electricity compared to the households in Chawama. The houses in Kabulonga are bigger and have more rooms that need lighting, cooling and heating which are rarely found in Chawama.

\subsection{Sustainable Energy}

Sustainable energy can be defined as energy that cannot be depleted, that does not cause harm to the environment and that reduces greenhouse gas emissions $[13,14,19]$. The transition to sustainable energy resources and systems provides an opportunity to address multiple environmental, economic, and development needs. From an environmental perspective, it is becoming increasingly clear that humanity's current energy habits must change to reduce significant public health risks, avoid placing intolerable stresses on critical natural systems, and, in particular, to manage the substantial risks posed by climate change. By spurring the development of alternatives to today's conventional fuels, a sustainable energy transition could also help to address the energy security concerns that are again at the forefront of the Zambian government, thereby reducing the likelihood of competition for unsustainable biomas and fossil fuel resources. Finally, increased access to clean, affordable, high-quality fuels and electricity could generate multiple benefits for the world's poor, easing the day-to-day struggle to secure basic means of survival; enhancing educational opportunities; reducing substantial pollution-related health risks; freeing up scarce capital and human resources; facilitating the delivery of essential services, including basic medical care; and mitigating local environmental degradation [15].

The Zambian government recognizes the importance and availability of modern, reliable efficient and sustainable energy sources as key drivers to development, the government is focussing on reducing poverty, health, education and unemployment challenges just like other African developing countries [14].

\subsection{Conceptual Framework}

The conceptual framework below graphically depicts the causes of power deficits in Zambia. According to the figure, one of the causes of power deficit is the inadequate production by Zambia Electricity Supply Corporation (ZESCO) the utility company that provides the services. Considering the production capacity of the machinery that ZESCO has and also the availability of various water bodies in the country that can be a source of hyro-energy, one would state that the production of electricity is inadequate. The other reason that is related to inadequate supply is the increased demand of electricity. The high demand of electricity in the country has created a big gap between the quantity of electricity supplied and the actual demand in the country. The high demand has been caused by the high economic activities that the country is currently engaged in various industries. On the other hand, ZESCO's inability to adequately manage the machinery in the already existing hydro stations has also largely contributed to the poor performance of the utility company in supplying electricity thereby causing power deficits in the country.

The figure also shows the effects of power shortages, the effect culminated into power rationing the utility company engages into. Furthermore, the figure shows the relationship between power rationing as the independent variable and productivity at household and industrial level.

The figure postulates that when there is power rationing in effect, households and industries are off electricity supply during the period of power rationing.

During this period production does not take place because industries need electricity to drive their productive equipment. The case is not different at household level, as the production of meals and also any satisfaction that comes from the usage of electricity is distorted. Repeated power rationing has an adverse effect that eventually leads to decline in productivity in industries and consequently the failure by industries to reach the sales volumes. Reduced sales volume translates into reduced income because firms are unable to produce enough of their production to meet targeted sales volumes. And when then the incomes are low, it trickles down to the households being affected as well because the labour force that operates in these industries are from specific housing units that can feel the double effect of electricity outages. 


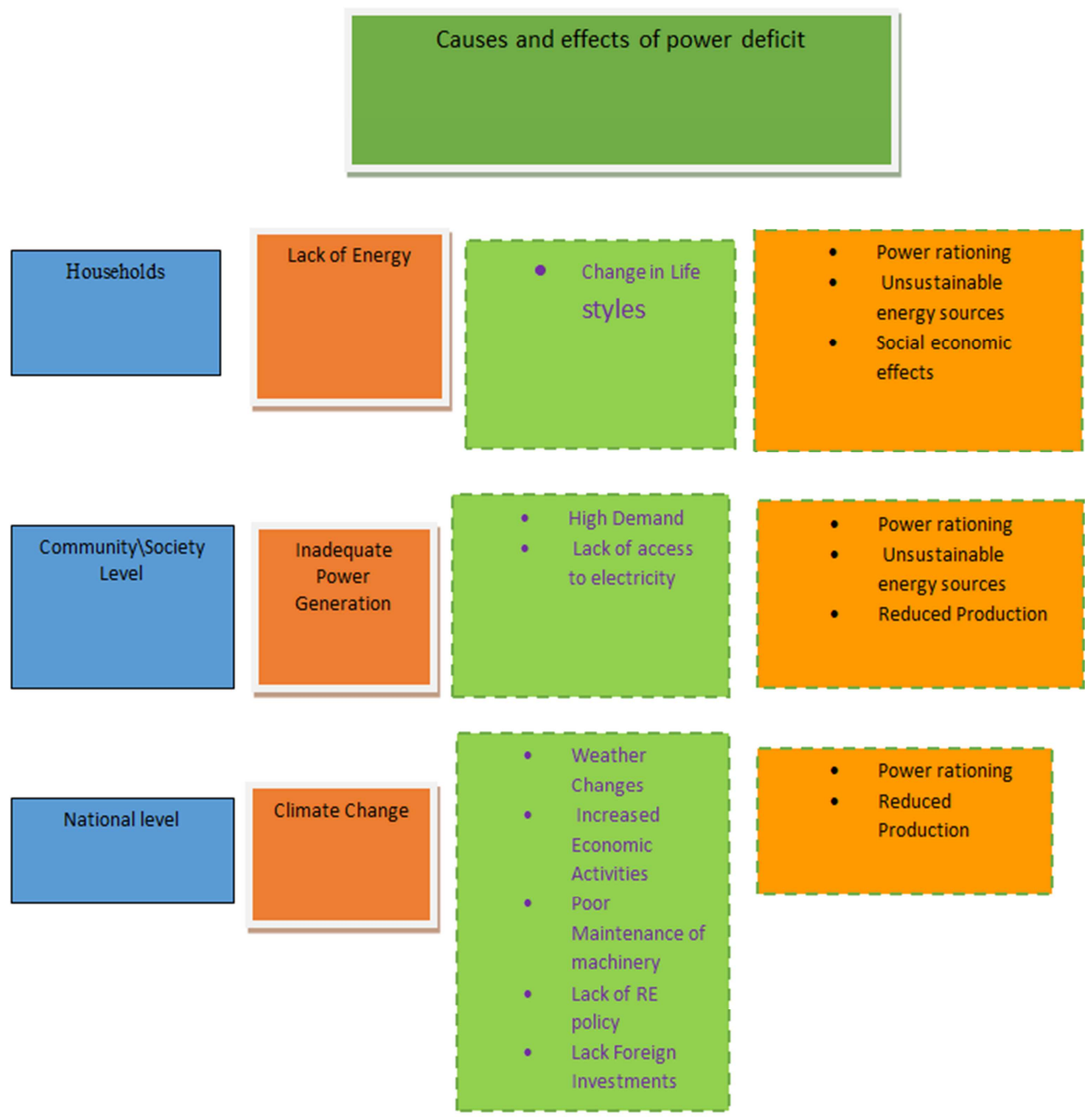

Figure 4. Model of the Conceptual framework of the study.

\section{Overview of Zambia's Energy Sector}

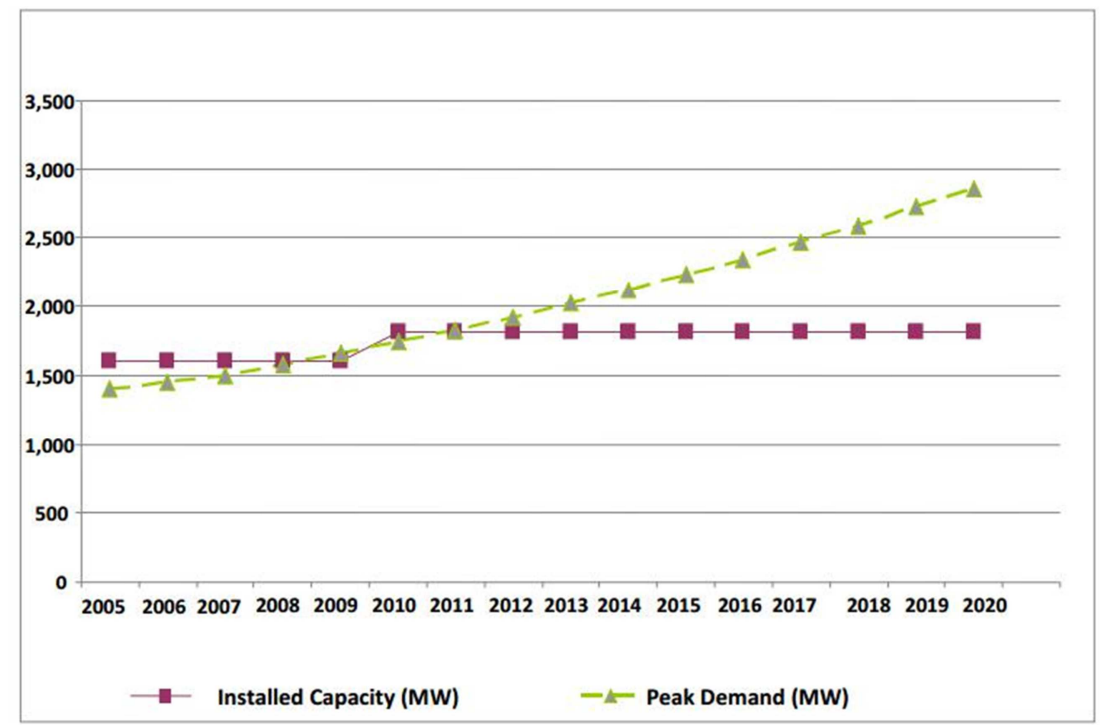

Source: ZDA (2014)

Figure 5. Electricity Demand Projections. 
Zambia's energy sector is made up of; electricity, petroleum, coal, biomass, and renewable energy. While most of these energy sources are available within, petroleum is wholly imported. With a national electrification rate of $26 \%$, $25 \%$ is consumed by households in urban areas while in rural areas the electrification rate is at 3\% [8-16].

According to the official estimates shown in the figure 5 below, the electricity demand grew by an average rate of $3.5 \%$ in the period from 2002 to 2010 with the mining sector being the main consumers of the electricity at $54.8 \%$, residential at $30.3 \%$, commerce and industry sectors at $15 \%$ and the rest exported, social and agriculture sectors respectively. The figure also shows the electricity demand projections up to the year 2020 [9].

\section{Current Power Generation in Zambia}

As already mentioned in the overview above, Zambia's electricity generation mix is dominated by hydro generation which accounts for more than 95 percent. The electricity generation mix is comprised of hydro, diesel, thermal, solar and Heavy Fuel Oil (HFO). The hydro generation mix comprises major and mini power stations [3-21]. ZESCO owns the bulk of the generation stations while the rest are owned by Independent Power Producers (IPPs).

In 2014, the total installed capacity in Zambia was 2,396MW disaggregated as follows: hydro 2,255MW; thermal 80MW; diesel 11MW; HFO 50MW and solar $0.06 \mathrm{MW}$. This was in comparison to a total of $2,038 \mathrm{MW}$ in 2013. The increase in total installed capacity was attributed to the commissioning of the 360MW Kariba North Bank Extension (KNBE) power station. Total electricity generation in 2014 was $14,453 \mathrm{GWh}$, compared to $13,299 \mathrm{GWh}$ in 2013 , representing an increase of 8.7 percent. During the year under review (as was the case in 2013), there were three (3) operational private IPPs, namely LHPC; Ndola Energy Company Limited (NECL); and Zengamina Power Limited (ZPL).

\subsection{Generation from Major Hydropower Stations}

ZESCO owns four (4) major hydropower stations and these are: Kafue Gorge; Kariba North Bank; Kariba North Bank Extension; and Victoria Falls. The installed capacities are $990 \mathrm{MW}, 720 \mathrm{MW}$, 360MW and 108MW, for Kafue Gorge; Kariba North Bank; Kariba North Bank Extension; and Victoria Falls, respectively.

Total generation output from ZESCO's major hydropower stations increased by 6.7 percent, from $12,780 \mathrm{GWh}$ in 2013 to $13,638 \mathrm{GWh}$ in 2014 . The increase in generation was boosted by the commissioning of Kariba North Bank Extension power station with a rated capacity of $360 \mathrm{MW}$.

\subsection{Generation from Mini Hydropower Stations}

In 2014, the total number of mini hydropower stations was five (5). These were Lusiwasi; Musonda Falls; Chishimba
Falls; Shiwan'gandu; and Lunzua power stations. The installed capacities of these plants were: $12 \mathrm{MW}$; $5 \mathrm{MW}$; 6MW; 1MW; and 0.75MW for Lusiwasi; Musonda Falls; Chishimba Falls; Shiwan'gandu; and Lunzua, respectively.

\subsection{Generation from Diesel Power Stations}

Diesel power stations comprise Chavuma; Zambezi; Kabompo; Mufumbwe; Mwinilunga; Lukulu; Shang'ombo; and Luangwa. The total installed capacity for diesel power stations was $11.3 \mathrm{MW}$ in 2014 compared to $10.6 \mathrm{MW}$ in 2013. The increase in installed capacity was mainly on account of additional capacity from Shang'ombo diesel power station. The installed capacities were as follows: $1 \mathrm{MW} ; 2.35 \mathrm{MW}$; 1.55MW; $0.9 \mathrm{MW} ; 1.5 \mathrm{MW} ; 1.5 \mathrm{MW} ; 1 \mathrm{MW}$ and $1.5 \mathrm{MW}$ for Chavuma; Zambezi; Kabompo; Mufumbwe; Mwinilunga; Lukulu; Shangombo; and Luangwa, respectively. Total generation sent out from ZESCO's diesel power stations reduced by 6.5 percent between 2013 and 2014 .

\subsection{Generation from Independent Power Producers}

During the year under review, there were three (3) operational Independent Power Producers (IPPs), namely: LHPC; NECL; and ZPL. LHPC owns Mulungushi and Lunsemfwa power stations. In 2014, the total installed capacity from these IPPs was $106.8 \mathrm{MW}$ compared to $105 \mathrm{MW}$ in 2013. The installed capacity for the power stations was as follows; LHPC (56MW); NECL (50MW); and ZPL (0.75MW).

\section{Alternative Potential Energy in Zambia}

\subsection{Biomass}

Zambia has a total biomass resource and economic bioenergy potential of 2.15 million tonnes, and $498 \mathrm{MW}$, respectively [9]. The largest contribution is from agriculture waste, which registered $90 \%$ of total potential followed by forest waste with $9.3 \%$. ZESCO, in conjunction with United Nations Industrial Development Organisation (UNIDO), had planned to install a $1 \mathrm{MW}$ biomass electricity generation plant to meet the electricity needs of Kaputa District. This facility was meant to replace $440 \mathrm{KW}$ installed capacity of a diesel power generation system. ZESCO has since extended the national grid to Kaputa, resulting in the concept being taken over by the CEC, which will utilise feedstock from sawmills on the Copperbelt. Another on-going biomass-based electricity generation activity in Zambia is being implemented at Nakambala Sugar.

\subsection{Solar Energy}

Zambia has an average solar insolation of 5.5 $\mathrm{kWh} / \mathrm{m} 2 /$ day, with approximately 3,000 sunshine hours annually, providing good potential for solar thermal and photovoltaic applications. A preliminary solar energy 
potential assessment for Zambia was undertaken using Geographic Information System data. Red regions have the highest solar irradiance values up to $2,750 \mathrm{kWh} / \mathrm{m} 2$. Zambia's northern areas recorded the highest global solar irradiation of $2,300 \mathrm{kWh} / \mathrm{m} 2 /$ year [10-16].

The REA has developed a solar mini-grid in Samfya District, Luapula Province. The solar mini-grid project is expected togenerate $60 \mathrm{KW}$ of electricity, which will be supplied to a cluster of villages in the Mpata fishing community, which has an estimated total population of 6,000 people and 617 households. The project is being implemented under a loan facility agreement between the Development Bank of Zambia (DBZ) and the REA. The interest-free loan from the Development Bank of Zambia was facilitated by UNIDO, under the Global Environment Facility (GEF) agreement.

The REA is providing part of the investment cost for the project. The government of Zambia has received tenders from various institutions to develop a total of $30 \mathrm{MW}$ solar photovoltaic (PV), comprising $10 \mathrm{MW}$ in the North-Western Province, $10 \mathrm{MW}$ in Eastern Province, and $10 \mathrm{MW}$ in Luapula on a build-own-operate (BOO) model. The bid process is still to be implemented and a policy is required to leverage tariffs currently being charged by ZESCO for ongrid customers.

\subsection{Geothermal}

Historic surveys have identified over 80 hot and mineralised springs in Zambia. Subsequently, a detailed study by an Italian-Zambian joint venture in the mid- 1980s identified five prospective sites. Kalahari GeoEnergy Ltd., a self-funded private company, entered into an agreement with Government of Zambia in March 2011 under which the company would undertake geothermal research, exploration and development. The company has conducted field reconnaissance including hydrochemistry on all identified geothermal targets, and geophysics on the more prospective targets. Having formulated a conceptual model, Kalahari GeoEnergy will conduct preliminary drilling at its first target, which is a low enthalpy system in a shallow sedimentary setting. It is anticipated that reservoir modelling and a test well will be completed during 2013 and a feasibility study will be completed in 2014 .

By targeting low-enthalpy geothermal systems, Kalahari GeoEnergy expects to be able to define a number of commercially viable geothermal sites across Zambia, which would provide both on-grid and off-grid power production capability, thus potentially benefiting both established users and the rural electrification and industrialization programmes. Also, by using modular binary power plants, feasible targets can be brought into production more quickly at a lower capital cost than for large direct steam-fed turbines

In spite of these efforts, more work is required on comprehensive resource assessments to guide policy formulation to support geothermal energy; including building capacity to design, build, operate and maintain geothermal plants in Zambia, along the lines that Kenya has developed in using this technology. South-South co-operation with regards to an exchange of resources, technology and knowledge with Kenya is commended, but should culminate in technology transfer in addition

\subsection{Wind Energy}

Wind speeds in Zambia average 3 metres per second $(\mathrm{m} / \mathrm{s})$ at $10 \mathrm{~m}$ above the ground, a speed which is mainly suitable for mechanical applications [16]. Some meteorological building capacity and skills data on wind speeds at $10 \mathrm{~m}$ above ground is available, but is not adequate to guide investment for power generation. At that height, wind energy is only useful for mechanical energy, such as water pumping.

Indications that higher wind speeds may exist at higher heights, e.g., $70 \mathrm{~m}$ to $100 \mathrm{~m}$, needs to be explored to direct any strategy to develop wind in Zambia. Encouraging wind hotspots at a higher altitude were identified from a recent SADC study (2012), the Renewable Energy Strategy and Action Plan, around Chongwe area east of Lusaka (Location: $28^{\circ} 47^{\prime} 40^{\prime \prime}$ East, $15^{\circ} 30^{\prime} 45^{\prime \prime}$ South), and along the Muchinga escarpment centred on Chipembele (Location: 31 $28^{\prime}$ 57" East, $12^{\circ} 1^{\prime} 53 "$ South).

\section{Empirical Evidence}

Existing evidence shows that energy consumption in households in low and high density areas is based on the different factors such as; behaviours of household occupants, psychology (including the marketing-related literature on consumer behaviour) and sociology. Such analyses on the diffusion of energy-efficient activities typically include factors related to the following [11-17]: (1) characteristics of the household (occupants), (2) characteristics of the residence, (3) characteristics of the measure (technology), (4) economic factors, (5) weather and climate factors, (6) information diffusion, (7) attitudes/preferences towards the environment. In light of the interdependencies among factors (and categories), causal impact of individual variables (or concepts) cannot always be clearly identified or distinguished. Among others, [7-11] point out that energysaving measures may be divided in (i) low-cost or no-cost measures which do not involve capital investment but rather behavioral change (for example, switching off lights, substituting high energy lamps for energy savers light bulbs) and (ii) measures which require capital investment and involve technical changes in the house (thermal insulation of built environment, windows with double or triple-glazing). Purchasing a new appliance usually does not require technical changes in the house, but purchasing expenditures may be high.

\section{Research Methodology}

\subsection{Research Design and Study Areas}

The research employed a non-intervention research design, in particular descriptive studies. This design was used 
because the investigation took place in an uncontrolled setting; that is, residents of Lusaka city in Zambia. The research adopted this design due to the fact that the findings of the research endeavoured to make descriptions based on actual events without undue influence of intervention whatsoever. This approach required the use of both qualitative and quantitative methodologies to paint a full picture relating to the available energy alternatives and assess their sustainability in Zambia.

The study was conducted in Lusaka and the target areas were: Kabulonga and Chawama these being high and low density areas respectively. This was the primary data collected from end users of electricity and other alternative power/energy sources.

\subsection{Description of Population and Sample Size}

The sample of the study was drawn from two (2) major residential areas Kabulonga and Chawama. An online sample size calculator with confidence interval of 5 and confidence level of $95 \%$ was used to determine the sample size of the study. The two areas provided a well-represented sample. Simple random sampling was carried out in both Kabulonga and Chawama. From the picked households, the heads of households were targeted to investigate the types of alternative energy utilised by their household.

The sample size consisted of 90 respondents who were residents of Lusaka District drawn from Kabulonga and Chawama. The sample was large enough to represent the views of consumers of energy in Lusaka and was also a convenient size given the availability of resources and short period of time the study was conducted. Furthermore, the sample size was manageable, easy to control, cost effective and data was analyzed and generalized without complications.

In addition to the consumers, data was also collected from key informants at the Ministry of Energy, Energy Regulation Board of Zambia (ERB), Zambia Electricity Supply Corporation limited (ZESCO) and Key suppliers of alternative sources of energy such as solar and fuel powered and high energy consumers in the manufacturing

\subsection{Data Collection}

In order to for the study to explore and analyse the available energy alternatives and assess their sustainability in Zambia, the study used both primary and secondary data. The study collected primary data in two-folds which included qualitative and quantitative data collection. In addition, documentation reviews were done on different sources of energy.

\subsection{Qualitative Data Collection}

The data was collected through in-depth interviews and direct observation. The data mainly focused on the historical background of the power deficit problems, the current energy sources situation and the perception and views over the use of alternative energy sources and their sustainability. In addition, the study used key informant interviews to collect data on new potentials and opportunities generated by the presence of other sources of energy in Zambia.

\subsection{Quantitative Data Collection}

The study also collected quantitative data from consumers of different types of energy in Zambia. Two residential areas were targeted in the collection of quantitative data using a questionnaire. The study collected data from 90 respondents.

\subsection{Quantitative Data Analysis}

Considering the fair size of the sample, the data that was collected using the questionnaires was checked for uniformity, consistency and accuracy. The data was analysed using statistical package for social sciences software (SPSS) via a data entry query for analysis. Frequency tables, graphs and cross tabulations were then produced. Frequency tables and graphs were used to facilitate data presentation. Consequently, the mentioned software package is favoured for these task because it is user friendly, capable to handle large numbers, most suitably programmed for the analysis of quantitative data, and is perceived as being efficient as it allows for cross tabulation of numerous variables.

\subsection{Qualitative Data Analysis}

Data analysis was done using content analysis thus no computer software was used to analyze the data. Content analysis involved analyzing responses as they were given by the respondent. Responses gathered from interview guides were analysed using content from the responses. The researcher carefully went through the descriptive responses given by participants to each question in order to identify broad themes that emerged from the research findings.

The study then assigned codes to the main themes and after identifying the themes, the researcher went through the transcripts of all the interviews and classified the responses under the different themes. The final step involved integrating themes and responses into the text of the report; while discussing the main themes that emerged from the research findings.

\subsection{Ethical Consideration}

The study considered all the research ethics by introducing the researchers, the objective of the study and any benefit or risk for participating in the research before study participants/respondents. The study made sure that the information that was collected remained confidential and there was no disclosure of names or any identification among the respondents. Consent was obtained to make sure that respondents were willing to participate in the interview. Participation in the study was entirely voluntary and as such participants were free to stop the interview even before the interview ended. 


\section{Analysis and Presentation of Findings}

This section presents qualitative and quantitative information collected from respondents of two areas in Lusaka namely Kabulonga and Chawama. The information is presented in frequency tables and charts.

Table 1. Occupancy Head Count in Areas of Interest.

\begin{tabular}{lll}
\hline Number of persons in households & Frequency & Percent \\
\hline $1-5$ & 50 & 55.6 \\
$6-10$ & 40 & 44.4 \\
Total & 90 & 100.0 \\
\hline
\end{tabular}

Table 1 shows the number of persons living in households, results showed that $55.6 \%$ of the respondents had 1 to 5 persons living in a household and $44.4 \%$ had 6-10 people living in the household.

\subsection{Education Background in Kabulonga and Chawama}

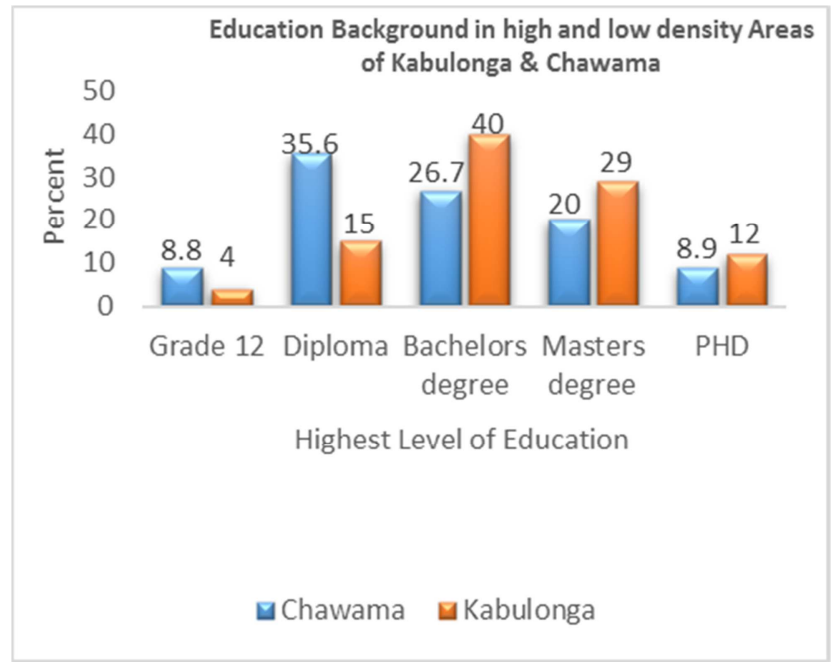

Figure 6. Percent distribution of Education background in high and low density areas.

Figure 6 shows the highest level of education among selected household heads in Kabulonga and Chawama. Results showed that the majority of respondents said they had bachelor's degree as their highest level of education, that is $40 \%$ in Kabulonga and $26.7 \%$ in Chawama and the lowest being Grade 12 at $8.8 \%$ Chawama and $4 \%$ in Kabulonga. It was further found that Chawama had more diploma holders at $35.6 \%$ against $15 \%$ in Kabulonga.

\subsection{Education Background and Use of Energy Sources by Residential Area}

Table 2. For Kabulonga (Education Background against energy) out 45.

\begin{tabular}{llllll}
\hline & G12 & Dip & Degree & Master & Doctorate \\
\hline Gas & $7.5 \%$ & $9.8 \%$ & $34.3 \%$ & $26.4 \%$ & $22 \%$ \\
Electricity & $21 \%$ & $17 \%$ & $30 \%$ & $26 \%$ & $6 \%$ \\
Solar & $50 \%$ & $50 \%$ & 0 & 0 & 0 \\
Generator & $6.4 \%$ & $10.2 \%$ & $32.6 \%$ & $32.4 \%$ & $18.4 \%$ \\
Charcoal & $27 \%$ & $23 \%$ & $24 \%$ & $18 \%$ & $8 \%$ \\
\hline
\end{tabular}

Table 3. For Chawama (Education Background against energy) out 45.

\begin{tabular}{llllll}
\hline & G12 & Dip & Degree & Master & Doctorate \\
\hline Gas & $3.5 \%$ & $22.2 \%$ & $28 \%$ & $20.1 \%$ & $26.2 \%$ \\
Electricity & $13 \%$ & $24.8 \%$ & $29 \%$ & $20 \%$ & $13.2 \%$ \\
Solar & $50 \%$ & $50 \%$ & 0 & 0 & 0 \\
Generator & $14.4 \%$ & $10 \%$ & $23 \%$ & $25 \%$ & $27.6 \%$ \\
Charcoal & $31.5 \%$ & $24.4 \%$ & $20.1 \%$ & $16 \%$ & $8 \%$ \\
\hline
\end{tabular}

The two tables above show the percentage of source of energy used in the two areas in relation to the education backgrounds of the household heads. It can be seen from the results that the education background of household heads plays a very minor role in decision making of what source of energy is used in the households. This is because there are no major differences in the sources of energy used.

\section{Percentage share of energy sources used in households}

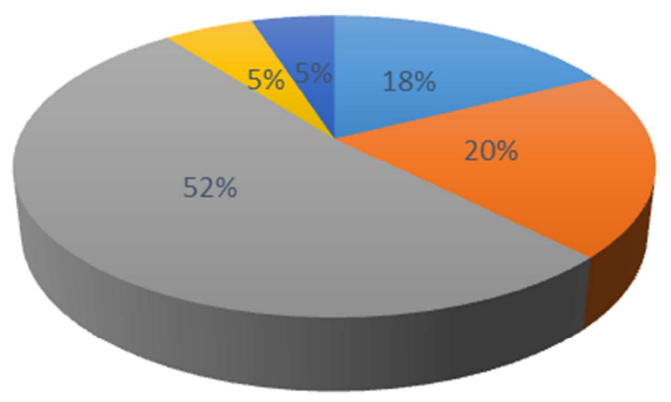

घharcoal $\square$ Gas $\square$ Electricity $\square$ Generator $\square$ Solar

Figure 7. Percentage share of the type of energy used in households.

Figure 7 shows the types of energy sources used in households. It was revealed that $52 \%$ use electricity, $20 \%$ of the respondents said they use gas, $18 \%$ use charcoal and 5\% use gas and solar respectively.

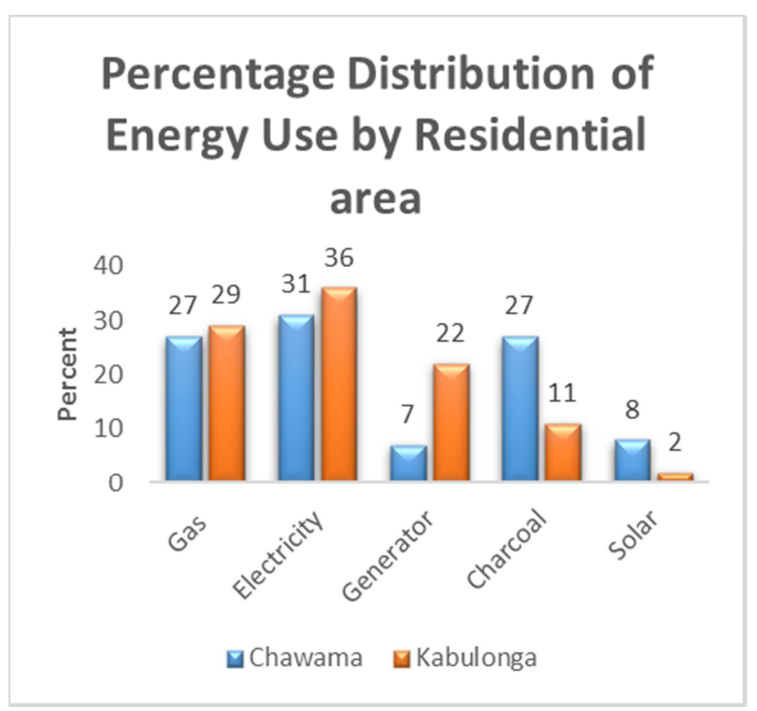

Figure 8. Use of energy sources by residential areas. 
Figure 8 shows the use of energy sources by residential area. It can be seen from the results above that $29 \%$ the respondents in kabulonga use gas while a lower percentage of $26 \%$ in Chawama use gas in their households. $36 \%$ of the respondents in kabulonga use electricity against $31.1 \%$ of respondents in Chawama. The findings further showed that $22 \%$ in Kabulonga use generator against $6.7 \%$ in Chawama. It was noted though that more respondents in Chawama use solar $8.9 \%$ against $2 \%$ in Kabulonga and also that those that use charcoal in Chawama $26.7 \%$ were more than the Charcoal users in Kabulonga at 11\%.

\subsection{Means Test of Energy Usage by Residence}

Table 4. Means test of energy usage by residence.

\begin{tabular}{lllll}
\hline Source of energy & Kabulonga & Chawama & Difference & P value \\
\hline Gas & 0.29 & 0.27 & 0.02 & 0.969 \\
Charcoal & 0.11 & 0.27 & -0.16 & 0.781 \\
Generator & 0.22 & 0.07 & 0.15 & 0.718 \\
Solar & 0.02 & 0.09 & -0.07 & 0.15 \\
Hydro-electricity & 0.36 & 0.31 & 0.05 & 0.969 \\
\hline
\end{tabular}

The table above shows the significant relationship between residential areas and the use of energy sources. It can therefore be deducted that given the two hypothesis as below;

$\mathrm{H} 0$ : There is no difference in energy usage between the two areas.

H1: There is a difference in the usage of energy between the two areas.

Given a confidence level of $0.05(5 \%)$ set to be the margin of error, it can therefore be deducted as follows for the various sources of energy;

Gas - The null hypothesis at a P value of 0.969 (96.9\%) can be accepted and therefore concluded that there is no significant difference in the usage of gas as a source of Energy between Kabulonga and Chawama.

Charcoal: The null hypothesis can be accepted and concluded that there is no significant difference in the usage of charcoal between the two areas at a $P$ value of 0.781

Generator: At a $\mathrm{P}$ value of 0.718 , accept the Null hypothesis and conclude there is no significant difference in Generator usage among the two areas.

Solar: At a $\mathrm{P}$ value of $0.15(15 \%)$ given a confidence interval of $0.05(5 \%)$, we accept the null hypothesis. There is no significant difference in solar usage between Kabulonga and Chawama.

Hydro: At a P value of 0.969 , accept the null hypothesis and consequently conclude that there is no significant difference in hydroelectric usage between the two areas.

These results have far reaching effects in terms of policy formulation. While there could have been suppositions that usage of certain energy sources would significantly differ from one area to another based on factors like educational level, income etc, this research has come to the conclusive findings that there is no significant difference for our energy sources under study for the two areas.

\subsection{Amount Spent on Energy by Residential Area}

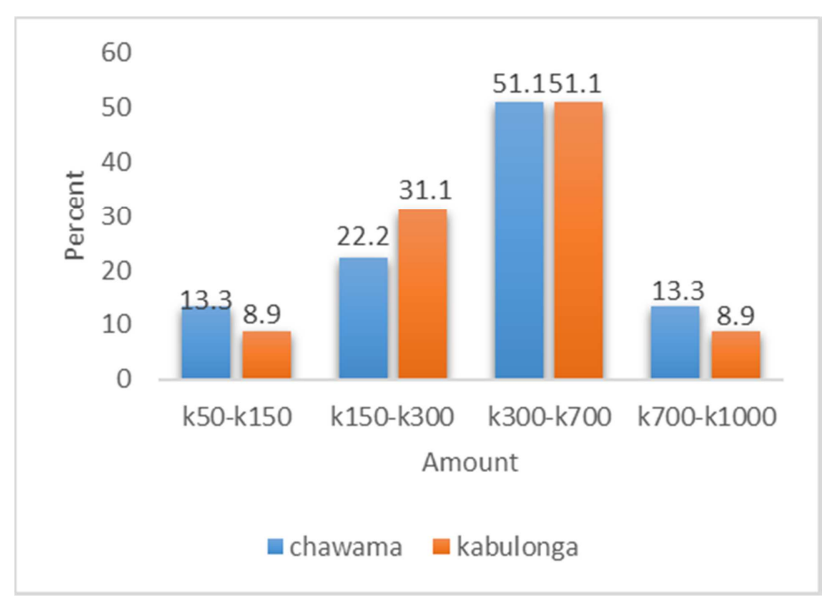

Figure 9. Opinions of residence on the amount spent on energy.

Figure 9 above showed that a majority of respondents from the two residential areas spend between K300 - K700. It was however, surprising that $13.3 \%$ spend between K700 - K1000 in Chawama against $8.9 \%$ in Kabulonga. $13.3 \%$ in Chawama said that they spend between K50 - 150 against the $8.9 \%$ in Kabulonga. $31.1 \%$ in Kabulonga claimed that they spend between K150 - K300 against 22.2\% for Chawama.

\subsection{Opinions of Residence on the Amount Spent on Energy by Residential Area}

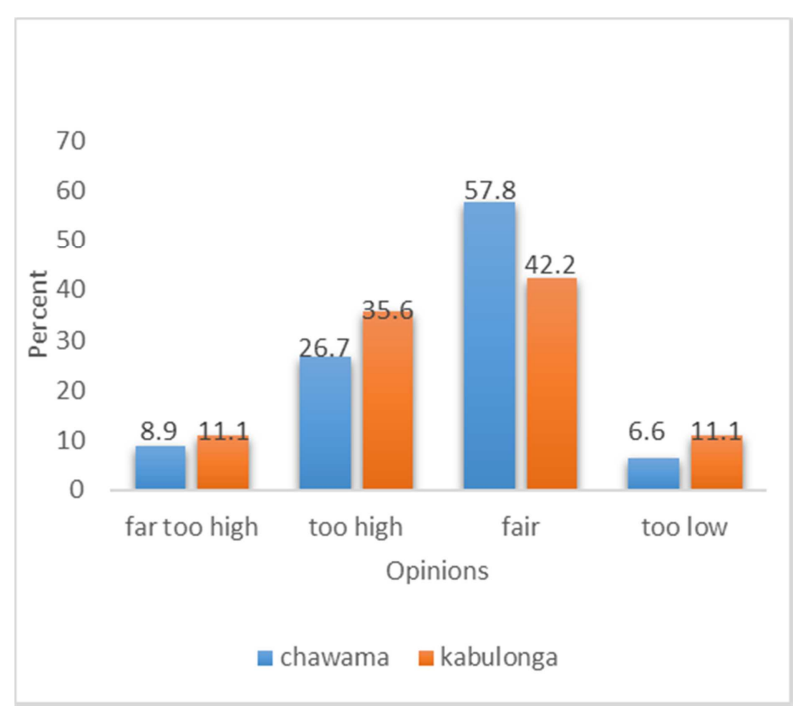

Figure 10. Opinions of residence on the amount spent on energy by residential area.

Figure 10 above shows respondent's view of what they spend on electricity each month. It is shown that $57.8 \%$ of the respondents in Chawama said that the amount spent on electricity each month is fair, while a lower percentage of $42.2 \%$ said its fair in Kabulong. Those that said it was too low were $6.6 \%$ for Chawama and 11.1 for Kabulonga. It was also revealed that $36 \%$ in Kabulong said that it was too high and $26 \%$ for Chawama. $11 \%$ for Kabulonga said it was too high against the $9 \%$ for Chawama. 


\subsection{Alternative Sources of Energy Zambia Should Prioritize According to the Respondents}

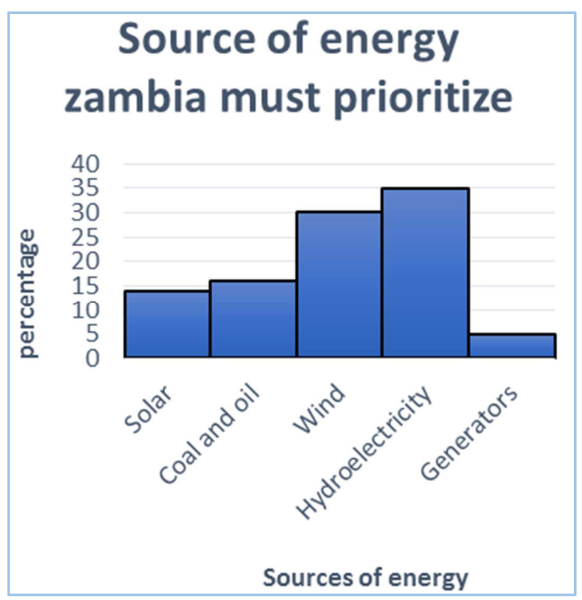

Figure 11. Alternative sources of energy Zambia should prioritize according to the respondents.

Figure 11 above shows respondents view on which source of energy Zambia must give priority to in the future. Results show that $35 \%$ of the respondents said hydroelectricity must be prioritized while $30 \%$ said solar energy, $16 \%$ said coal and oil and wind energy, while $5 \%$ said generators.

\section{Discussion of Findings}

The study on the sources of energy used in households revealed that the majority of the respondents $(97 \%)$ used electricity, $38.9 \%$ mentioned gas as a source of energy used, $35.6 \%$ used charcoal and $11 \%$ use generators. It was observed that nearly all respondents mentioned electricity as the main source, however, less than half said they used gas, charcoal and generators. It was also found that some households used a combination of electricity, gas, generators and charcoal. This can be attributed to the fact that Zambia's main source of energy has been hydroelectric power generation. A multi-nominal Logit model was used by some studies to analyses household energy choice decision. The most frequent categories use by such studies for the dependent variables include; biomass fuel, kerosene, electricity and liquefied petroleum gas. For instance, variables such as; household income, age of the household head, household size, residential area, level of education of the head of the household, were found to have a positive relationship with the household decision to use fire wood instead of kerosene.

The study further investigated how education background impacts on the sources of energy to be used in households. The study showed that respondents who had DegreelMaster Degree prefer electricity at $56.9 \%$ as the main source of energy compared to those with grade 12 and diploma at $43.1 \%$. It was also found that the respondents in Kabulonga used charcoal and gas as backup source while the two resources were used as the main sources in Chawama.

Further investigations on how much households are spending on energy, results revealed that slightly more than half 51 of the respondents spend between $\mathrm{k} 300-\mathrm{k} 700$ per month on energy. $26 \%$ spend between $\mathrm{k} 150-300$ and $11 \%$ spend between $\mathrm{k} 50-\mathrm{k} 150$ and $\mathrm{k} 700-\mathrm{k} 1000$. There was a noticeable characteristic in the number of persons per household in relation to the amount spent on energy. The majority of respondents representing $50 \%$ of the households said the amount spent on energy per month was fair, however some households $31 \%$ said the amount spent on energy compared to what they received was too high, and about $10 \%$ said the amount was far too high. This confirms the findings in this thesis that while many households are able to benefit from access to electricity services, May further states that low-income urban households still find the cost of the supply more than their budgets are able to sustain. This brings some difficulty for low-income households in keeping up with the pace of energy transition. Some households in most poor households switch between electricity and biomass fuels because of the cost and other related reasons.

\subsection{Conclusion}

From the study on the consumption and assessment of alternative energy sources usage in the two residential areas of Kabulonga being the low density area and Chawama being the high density area, it can be concluded that income and lifestyles in these households are key in making the decision as to which source of energy to use. The consumption of electricity in Kabulonga at $36 \%$ is higher than that of Chawama at $31 \%$. The majority of energy consumption in households is mostly consumed by computers lelectronics and cooking which takes up about $41 \%$.The electronic appliances such as air conditioners, computers, microwaves and electronic games \stoves are readily available in households in Kabulonga and may be a reason why the consumptionldemand for electricity is higher than in Chawama.

It was also observed that residents in Chawama use solar at $8 \%$ compared to $2 \%$ in in Kabulonga. It can be concluded that with the many electronic appliances in Kabulonga that need stable electricity, solar installation and connectivity turn out to be more expensive to setup hence the choice of electricity. The residents in Chawama resort to the usage of solar as they use it for activities such charging their phones and lighting which is cheaper for them than connecting to electricity.

It was also fund that the majority residents in Chawama use Charcoal at $27 \%$ compared to $11 \%$ in Kabulonga. It's a cheaper source though not sustainable as it leads to deforestation. Residents in Chawama also experience health problems and some even dying as a result of Indoor Air Pollution (IAP). Poverty has also contributed to the reason why charcoal is the main source for the people of Chawama. This further explains the reason why there is low access to electricity in high density areas like Chawama. The electricity connectivity fees are too high.

The climate changes and its effects are forcing the respondents to start looking for other cheaper and sustainable 
sources of energy such as solar. The people in the low density area (Kabulonga) have not been keen about solar because of the initial high investment needed at setup in spite of the government's initiatives of removing import duties on all solar equipment. The government has also introduced lower taxes on all energy efficient appliances as a way of promoting energy consumption sustainability

\subsection{Recommendations}

This research covered assessing the consumption and the sustainability of alternative energy sources available in low and high density areas of Kabulonga and Chawama. The respondents in both areas did not have enough knowledge on other sustainable and efficient consumption of energy except for the Hydro power and Charcoal. It is recommended that a detailed study be taken that will focus on awareness and benefits of these sustainable energy sources. The buying-in into solar other than depending on hydro power by the people in low density areas will reduce demand on the hydro power thereby increase production at commercial and household levels. It is also recommended that future studies should look at how Zambia can realize the vast potential in renewable energy such as solar.

\section{References}

[1] Bellanca, R., Bloomfield, E. \& Raj, K., 2013. Delivering Energy For Development. Warwickshire: Practical Action Publisning.

[2] Toth, F. L., 2012. Energy for Development. New York: Spring Science and Business Media.

[3] ERB, 2010. Energy Sector Report, Lusaka: s.n.

[4] Kariba Dam Case Study, 2000. Kariba Dam, Zambia and Zimbabwe, Lusaka: s.n.

[5] CSO, 2012. 2010 Census of Pouplation and housing: Population Summary Report, Lusaka: Central Statistical Office.

[6] Worlddometers, 2018. Worlddometers: Zambia Population. [Online] Available at: http: //www.worldometers.info/worldpopulation/zambia-population/ [Accessed 16 February 2019].
[7] Nyambe, I. \& Phiri, C., 2010. Database of Mineral Resources. Warsaw, University of Zambia.

[8] Owen, A. D., 2016. Policy Report on the Energy Sector in Zambia, Singapore: Energy studies Institute.

[9] ZDA, 2014. Zambia Energy Sector Profile, Lusaka: Zambia development Agency.

[10] Mwanza, M., Chachak, J., Cetin, N. S. \& Ulgen, K., 2016. Assessment of Solar Energy Source Distribution and Potential in Zambia. Periodicals of Engineering and Natural Resources, Volume 4 No 2.

[11] Wiel, S. \& McMahon, J. E., 2001. Energy-efficiency labels and Standards. Aguidebook for apliances, Equipment and Lighting.

[12] price waterhouse cooper, 2018. PWC. [Online] Available at: https: //www.pwc.com/zm/en/assets/pdf/zambia-budget2019.pdf [Accessed 7 January 2019].

[13] Brundtland, G., 1987. Our Common Future: Report of the 1987 World Commission on Environment and Development, Oslo: United Nations.

[14] UNDP, 2016. Industrialisation and Human Development Poverty Reduction Through Wealth and Employment Creation, Lusaka: UNDP.

[15] Singh, G., Nouhou, S. A. \& Sokona, M. Y., 2013. Zambia Renewables Readiness Assessment, Lusaka: IRENA.

[16] Owen, A. D., 2016. Policy Report on the Electricity Sector in Zambia, Singapore: Energy Studies Institute.

[17] Rennings, K. et al., 2013. Sustainable Energy Consumption In Residential Building. Heidelberg: Spring.

[18] Haanyika, C. M., 2016. Potential, Opportunities and Role of Energy Efficiency in Zambia. Lusaka, Utilink Limited.

[19] AFDB, 2016. Africa Development Bank (AFDB). [Online] Available at: https: //www.afdb.org/fileadmin/uploads/afdb/Documents/GenericDocuments/Zambia_Country_Profile.pdf [Accessed 20 January 2018].

[20] Haanyika, C. \& Mafayo, 2015. Energy Efficiency Roadmap for Zambia. Copenhagen, UNEP DTU.

[21] MEWD, 2008. National Energy Policy, Lusaka: Ministry of Energy and Water Development. 